\title{
Basin-scale comprehensive assessment of cadmium pollution, risk, and toxicity in riverine sediments of the Haihe Basin in north China
}

\author{
Wenzhong Tang ${ }^{\mathrm{a}, \mathrm{b}}$, Wenqiang Zhang ${ }^{\mathrm{a}}$, Yu Zhao ${ }^{\mathrm{a}}$, Hong Zhang ${ }^{\mathrm{a}, \mathrm{b}, *}$, Baoqing Shan ${ }^{\mathrm{a}, \mathrm{b}, *}$ \\ a State Key Laboratory of Environmental Aquatic Chemistry, Research Center for Eco-Environmental Sciences, Chinese Academy of Sciences, Beijing 100085, PR China \\ b University of Chinese Academy of Science, Beijing 100049, PR China
}

\section{A R T I C L E I N F O}

\section{Keywords:}

Cadmium

Surface riverine sediment

Ecological risk

Haihe Basin

Bioavailability

\begin{abstract}
A B S T R A C T
A comprehensive and detailed investigation of cadmium (Cd) pollution in surface riverine sediments of the Haihe Basin in north China was carried out. Total Cd concentrations in these sediments ranged from 0.153 to $22.1 \mathrm{mg} / \mathrm{kg}$, exceeding the soil background value at all sampling sites. The mean Cd concentration of the bioavailable fraction was $0.557 \mathrm{mg} / \mathrm{kg}$, accounting on average for $51.58 \%$ of the total Cd. A mean value of the $\mathrm{Cd}$ enrichment factor of 11.6 suggested that $\mathrm{Cd}$ has accumulated in most riverine sediments, resulting in a high degree of anthropogenic pollution. In fact, there were high levels of Cd pollution in the riverine sediments throughout the Haihe Basin, yielding geo-accumulation index values for Cd from 0.071 to 7.25. According to the potential ecological risk index, risk assessment code, and consensus-based sediment quality guidelines, $\mathrm{Cd}$ was a serious pollutant in this ecosystem. Because it occurred as a high proportion in the exchangeable/acid soluble fraction (21.21\% on average), it may also have biological toxicity. Our findings indicated that it is important to consider $\mathrm{Cd}$ in control strategies for managing riverine sediment pollution in the Haihe Basin.
\end{abstract}

\section{Introduction}

Sediments may provide a record of the history of heavy metal pollution in aquatic ecosystems (Shang et al., 2012; Zhang and Shan, 2008). A number of studies have shown that metal contamination of sediments is increasing, posing a serious threat to the health of aquatic systems globally (Kucuksezgin et al., 2008; Nobi et al., 2010; Zhang et al., 2014). Specifically, there is a great deal of concern over cadmium (Cd), a highly toxic metal (Gao et al., 2013; Nemati et al., 2011), found to occur in significant quantities in the sediments of many areas, such as Bohai Bay and Zhu River in China, and the Tibagi River in Brazil (Galunin et al., 2014; Gao and Chen, 2012; Tang et al., 2014). However, few researchers have conducted comprehensive and detailed investigations of Cd pollution, risk, and toxicity of riverine sediments on such a large scale as the Haihe Basin (with an area of $318,000 \mathrm{~km}^{2}$ ) of north China.

In China, heavy metal contamination of riverine sediments did not attract much attention from researchers or governments prior to the year 2000, and relatively few studies were carried out before this time (He et al., 1998; Zhao et al., 1999). Industrial and mining activities that always discharge heavy metals through atmospheric emissions or effluent into the rivers have been increasing continuously and rapidly, especially in the Haihe Basin (Tang et al., 2013). This area, located in northern China, is an important political, economic, and cultural center of China. The Haihe Basin includes nine major watersheds: Luan $\mathrm{He}$ (LH), Bei San He (BSH), Yong Ding He (YDH), Da Qing He (DQH), Haihe Gan-liu (HG), Zi Ya He (ZYH), Hei Long Gang (HLG), Zhang Wei He (ZWH), and Tu-hai Ma-xia He (TMH), as outlined by the Water Resources Protection Bureau of the Haihe Basin in China (WRPBHRB, 2011). To date, there have only been some studies of Cd pollution in the sediments of one or several rivers of a given watershed (Liu et al., 2009; Su et al., 2015; Tang et al., 2013). However, a comprehensive and detailed understanding of Cd concentrations, speciation, sources, pollution, risk, and toxicity across the whole basin is lacking. A study focusing on such these aspects will be very helpful in raising public awareness of Cd contamination, and in designing strategies to minimize pollution or exposure risk in the rivers of the Haihe Basin.

Using 220 sediment sampling sites within the Haihe Basin, this study was carried out to investigate: 1) Cd content and speciation in the surface sediments; 2) the Cd was of natural or anthropogenic origin, based on its enrichment factor (EF) and a Pearson correlation analysis (CA); 3) the degree of $\mathrm{Cd}$ pollution based on the geo-accumulation index $\left(I_{\text {geo }}\right)$; 4$)$ to assess the risk associated with Cd based on the potential ecological risk index ( $\left.E_{r}^{i}\right)$ and risk assessment code (RAC); and 5)

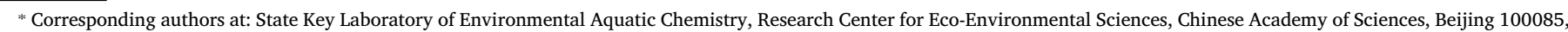
PR China.

E-mail addresses: wztang@rcees.ac.cn (W. Tang), hongzhang@rcees.ac.cn (H. Zhang), bqshan@rcees.ac.cn (B. Shan). 

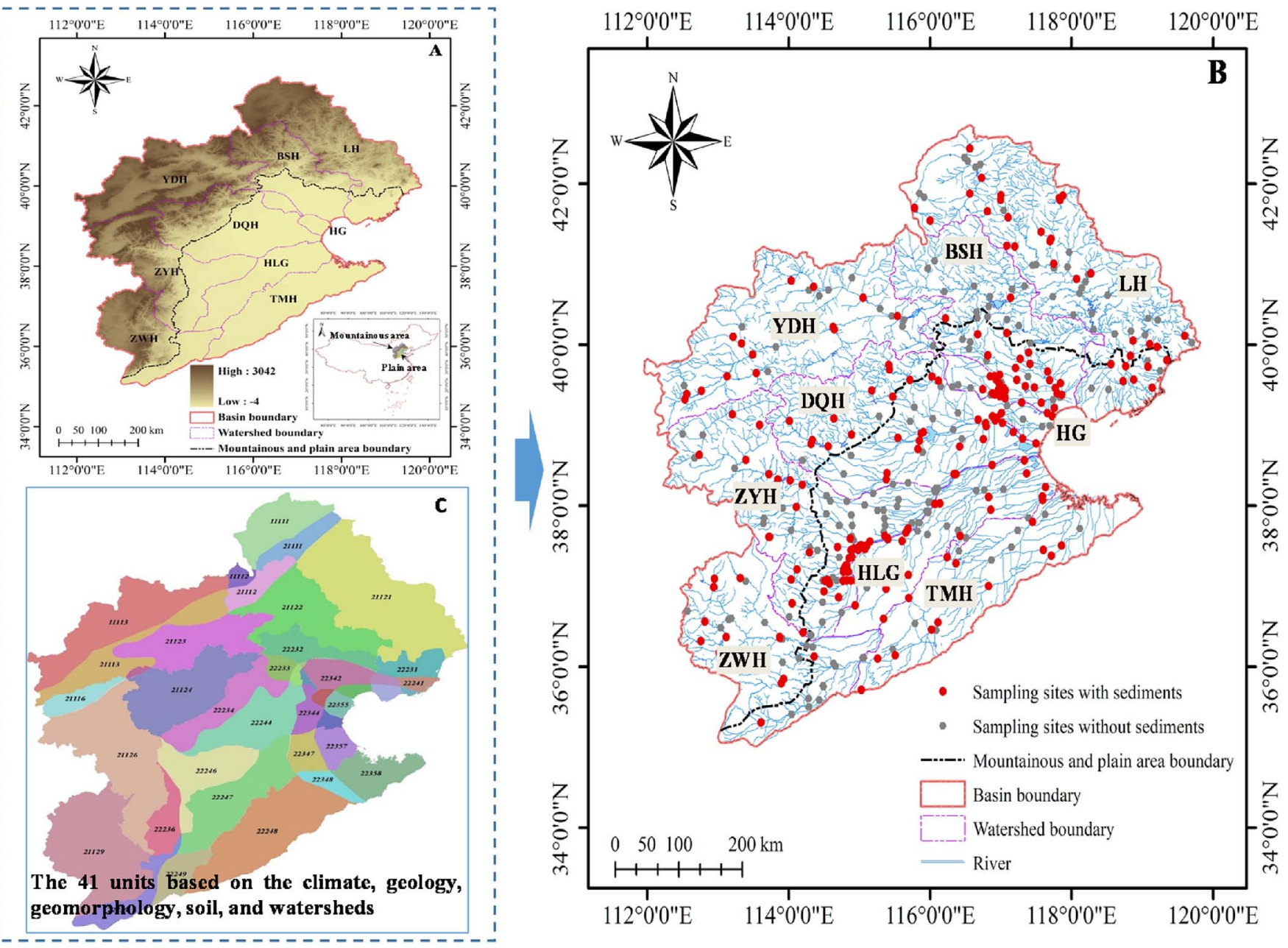

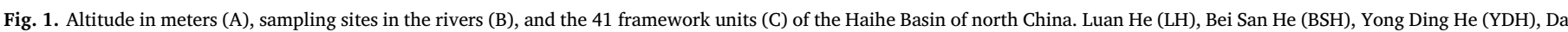
Qing He (DQH), Hai-he Gan-liu (HG), Zi Ya He (ZYH), Hei Long Gang (HLG), Zhang Wei He (ZWH), and Tu-hai Ma-xia He (TMH).

the potential biological toxicity of the sediments by consensus-based sediment quality guidelines (SQGs) and the mean probable effect concentration quotient $\left(Q_{m-P E C}\right)$. These investigations facilitated a basinscale analysis of the pollution status, risk and toxicity related to Cd in the riverine sediments of the Haihe Basin.

\section{Material and methods}

\subsection{Study area}

The Haihe Basin $\left(35^{\circ}-43^{\circ} \mathrm{N}, 112^{\circ}-120^{\circ} \mathrm{E}\right)$, located mainly within the province of Hebei, includes Beijing, Tianjin, parts of Inner Mongolia, and parts of the provinces of Shanxi, Henan, and Shandong (Fig. 1). This region has the highest population density in China, particularly in the plain region. The total population of the Haihe Basin is 130 million (11\% of the total Chinese population), and the GDP is USD $2.3 \times 10^{12}$ ( $12 \%$ of the total Chinese GDP). The annual average temperature in the basin ranges from 0 to $14{ }^{\circ} \mathrm{C}$. The annual average precipitation is $547 \mathrm{~mm}$, of which $75 \%-85 \%$ occurs from June to August (Ding et al., 2015).

Heavy industrial development and rapid urbanization have caused a great deal of pollution of surface waters in the Haihe Basin. As a result, this region has attracted much attention from the Chinese government and has been identified as one of the most important basins in the National 11th, 12th, and 13th Five-Year Plans for Water Pollution Control. The Haihe Basin contains approximately 113 rivers with a catchment area greater than $500 \mathrm{~km}^{2}$, comprising the nine major watersheds of the Water Resources Protection Bureau of the Haihe Basin in China (WRPBHRB, 2011).

\subsection{Sample collection and analysis}

Before selecting sampling sites, we divided the Haihe Basin into 41 units, reflecting climate, geology, geomorphology, soil, and watersheds. Using this framework of units, we selected sites to reflect the diversity of the river systems. In our study, 220 sampling sites with sediments were selected to investigate Cd pollution in the rivers of the Haihe Basin (Fig. 1). Thus, surface sediments $(0-10 \mathrm{~cm}$; triplicate samples at each site) were collected in the middle of the rivers from May to August of 2013 within the LH, BSH, YDH, DQH, HG, ZYH, HLG, ZWH and TMH watersheds, using a Peterson grab sampler. Of the original 410 sampling sites, sampling at approximately 190 sites was not pursued, because they had a hard riverbed composed almost completely of sand and gravel, had been dried up for many years, or had signs of environmental dredging carried out as sediment contaminant remediation (including sediment removal).

Each sediment sample was placed in a labeled acid-rinsed polyethylene plastic bag, and the samples were stored in an icebox to transport them to the laboratory. Each sample was then freeze-dried, ground, homogenized, passed through a 100-mesh sieve, and stored in a polypropylene bottle. These dried samples were stored at $-80{ }^{\circ} \mathrm{C}$ until they were analyzed. Concentrations of $\mathrm{Cd}, \mathrm{Fe}$, and $\mathrm{Mn}$ in the surface riverine sediments from all 220 sampling sites were determined (Fig. 1). Organic matter (OM) content was measured by residual titration with 
$\mathrm{K}_{2} \mathrm{Cr}_{2} \mathrm{O}_{7}$ (Bao, 2000), while the grain size of the sediments was measured with a laser particle size analyzer (Mastersizer 2000, Malvern, UK) over the range of $0.020-2000 \mu \mathrm{m}$. For total heavy metal analysis, sediment samples $(0.100 \mathrm{~g})$ were treated in a 5:1 mixture of hydrofluoric: perchloric acid (Tessier et al., 1979) by microwave digestion (MARS Xpress; CEM, Matthews, NC, USA); and the digestion conditions are listed in Table S1. The metal speciation in the sediments was determined using the modified European Community Bureau of Reference (BCR) three-step sequential extraction procedure; more detailed information is given in Table S2 (Arain et al., 2008; Nemati et al., 2011). This method provides the proportion of $\mathrm{Cd}$ present as B1 (exchangeable/acid soluble), B2 (reducible), B3 (oxidizable), and B4 (residual) fractions in the sediments. All of the above solutions were stored at $4{ }^{\circ} \mathrm{C}$ prior to analysis. Cd was measured by inductively coupled plasma-mass spectrometry (ICP-MS) (7500a; Agilent Technologies, Santa Clara, CA, USA), while $\mathrm{Fe}$ and Mn were measured by inductively coupled plasma-optical emission spectrometry (ICP-OES) (Optima 2000DV; PerkinElmer, Waltham, MA, USA). To ensure laboratory quality control, sediment reference materials (GBW07303a and GBW07436; National Institute of Metrology, Beijing, China) and triplicate samples were analyzed. Accepted recovery varied from $93 \%$ to $116 \%$, while precision was within $6 \%$ of the relative standard deviation (RSD).

\subsection{Relevant assessment and statistical analysis}

EF values were calculated to obtain information regarding the degree of enrichment of Cd in the sediments (Bhuiyan et al., 2010; Zhang et al., 2009). The pollution status and risks associated with Cd in surface sediments were assessed using the $I_{g e o}$ (Cheng and Yap, 2015; Christophoridis et al., 2009), and $E_{r}^{i}$ (Guo et al., 2010; Hakanson, 1980; Yi et al., 2011). Additionally, RAC, SQGs, and $Q_{m-P E C}$ values were used to evaluate sediment ecological toxicity by determining whether surface sediments were nontoxic or toxic to benthic organisms based on their Cd concentrations (Cheng and Yap, 2015; MacDonald et al., 2000; Perin et al., 1985). Details of these assessment methods are outlined in the Supplementary Materials (Table S3). Furthermore, Cd data were analyzed using SPSS Statistics 18.0 for Windows (IBM, Armonk, NY, USA), and a CA was used to assess relationships between $\mathrm{Cd}$, and $\mathrm{Fe}$, Mn, OM, and Mz. ArcGIS 10.1 (Esri, Redlands, CA, USA) was also used to process our experimental data.

\section{Results and discussion}

\subsection{Cadmium concentrations and speciation in the surface riverine sediments}

The spatial distribution of total Cd concentrations in the surface riverine sediments of the Haihe Basin is shown in Fig. 2. Total Cd concentrations ranged from 0.153 to $22.1 \mathrm{mg} / \mathrm{kg}$, with an average of $1.08 \mathrm{mg} / \mathrm{kg}$. Compared with data reported from other rivers in China and elsewhere globally (Table S4), the sediments of this study had high $\mathrm{Cd}$ concentrations. Spatially, the five regions with the highest Cd concentrations in the surface riverine sediments of the Haihe Basin were the northern region of the YDH watershed, the central region of the BSH watershed, the eastern region of the $\mathrm{ZYH}$ watershed, the eastern region of the ZWH watershed, and the junction region of HLG, TMH, and ZWH watersheds. The highest values were $3.90,13.3,9.86,11.9$, and $22.1 \mathrm{mg} / \mathrm{kg}$, respectively. Overall, Cd concentrations in the plain and coastal regions with heavy industrial development and rapid urbanization, especially near the cities were higher those than in the mountainous region of the Haihe Basin (Fig. S1).

The speciation of $\mathrm{Cd}$ in the sediments, determined by BCR sequential extraction, is shown in Fig. 3; while the percentage of total Cd occurring in the different fractions is shown in Fig. S2. Clearly, the majority of Cd occurred in the B1 and B4 fractions. In the surface riverine sediments of the Haihe Basin, the mean concentrations of $\mathrm{Cd}$ in the B1, B2, B3, and B4 fractions were $0.229,0.217,0.111$, and $0.523 \mathrm{mg} / \mathrm{kg}$, respectively, representing an average of $21.21 \%, 20.12 \%$, $10.25 \%$, and $48.42 \%$ of the total Cd concentrations, respectively. Spatially, concentrations of $\mathrm{Cd}$ in the $\mathrm{B} 1$ fraction were highest in the junction region of HLG, TMH, and ZWH watersheds (maximum value $=16.0 \mathrm{mg} / \mathrm{kg}$ ). The distribution of concentrations in the $\mathrm{B} 2$ fraction (maximum value $=3.52 \mathrm{mg} / \mathrm{kg}$ ) was similar to the $\mathrm{B} 1$ fraction. Interestingly, in the junction region of $\mathrm{YDH}, \mathrm{BSH}$, and $\mathrm{DQH}$ watersheds, and the junction region of HLG, TMH, and $\mathrm{ZWH}$ watersheds, the highest concentrations of Cd occurred in the B3 fraction.

\subsection{Cadmium sources and pollution in the surface riverine sediments}

The EF values of $\mathrm{Cd}$ were calculated to determine the potential sources of $\mathrm{Cd}$ in the surface riverine sediments of the Haihe Basin, (Fig. 4). The Cd EF values ranged from 0.249 to 211, with an average value of 11.6. The distribution of the EF values was similar to the total $\mathrm{Cd}$ concentrations within this basin. An EF value greater than 1.5 suggests that a significant portion of the metals originated from noncrustal or anthropogenic sources in the sediments (Li et al., 2010). Clearly, Cd was anthropogenically enriched in most sediments of the Haihe Basin (having EF values > 1.5), indicating a high degree of anthropogenic pollution in this basin. Therefore, EF may be a useful indicator of the role of anthropogenic processes in generating the $\mathrm{Cd}$ distribution in surface riverine sediments of the Haihe Basin. In addition, $\mathrm{Cd}$ in an ionic form, bound to carbonates, and in the exchangeable fraction, is released to the $\mathrm{B} 1$ fraction. This represents the fraction most easily enriched in sediments; it is also the fraction most easily re-mobilized, when environmental conditions change (Nemati et al., 2011). Therefore, $\mathrm{Cd}$ in the $\mathrm{B} 1$ fraction should receive more attention during development of effective control strategies for $\mathrm{Cd}$ pollution in riverine sediments.

CA is also a convenient way to identify the factors controlling heavy metal concentrations and their possible sources (Chai et al., 2015; Dragovic et al., 2008). Therefore, correlations between Cd and other sediment properties are presented in Table S5. As shown in Figs. S3-S6, the ranges and mean values of $\mathrm{Fe}, \mathrm{Mn}$, and $\mathrm{OM}$ contents in the surface riverine sediments are as follows: $\mathrm{Fe}, 0.350 \%-16.2 \%(3.69 \%)$; $\mathrm{Mn}$, $11.9-4500(685) \mathrm{mg} / \mathrm{kg}$; and $\mathrm{OM}, 0.285 \%-31.37 \%$ (5.01\%). Additionally, mean grain size $(\mathrm{Mz})$ of the riverine sediments ranged from 7.98 to $426 \mu \mathrm{m}$, with an average diameter of $68.4 \mu \mathrm{m}$. The correlations between different fractions of $\mathrm{Cd}$ in the sediments were complex. The total Cd content was significantly positively correlated with the percentage of Cd occurring in each different fraction ( $p<0.01$ ), except for the B3 fraction. Moreover, positive correlations among the B1 fraction $\mathrm{Cd}, \mathrm{B} 2$ fraction $\mathrm{Cd}$, and $\mathrm{B} 3$ fraction $\mathrm{Cd}$ indicated they all had the same anthropogenic sources, possibly including mining activities, battery production, and agricultural fertilizers. OM content was significantly positively correlated with the concentration of Cd in the B3 fraction $(\mathrm{p}<0.01)$, indicating a strong association of oxidizable $\mathrm{Cd}$ with OM (Quenea et al., 2009). No correlations were observed between $\mathrm{Cd}$ and Fe, Cd and Mn, or Cd and Mz.

Here, the $I_{\text {geo }}$ value was used to verify the degree of Cd pollution in the sediments (Fig. 4). According to this measure, there were high levels of Cd pollution in most of the riverine sediments; the $I_{\text {geo }}$ values for $\mathrm{Cd}$ ranged from 0.071 to 7.25 , with an average of 2.25 . These values indicate moderately to strongly polluted sediments in these rivers. The percentages of the $I_{\text {geo }}$ values occurring within the intervals $0-1,1-2$, $2-3,3-4,4-5$, and > 5 were $13.63 \%, 23.64 \%, 45.91 \%, 12.27 \%, 1.82 \%$, and $2.73 \%$, respectively. These findings showed that the riverine surface sediments of the Haihe Basin had been heavily contaminated with $\mathrm{Cd}$, because of anthropogenic inputs, consistent with the EF results.

\subsection{Cadmium risk and toxicity in the surface riverine sediments}

The risk associated with Cd in the surface riverine sediments of the 


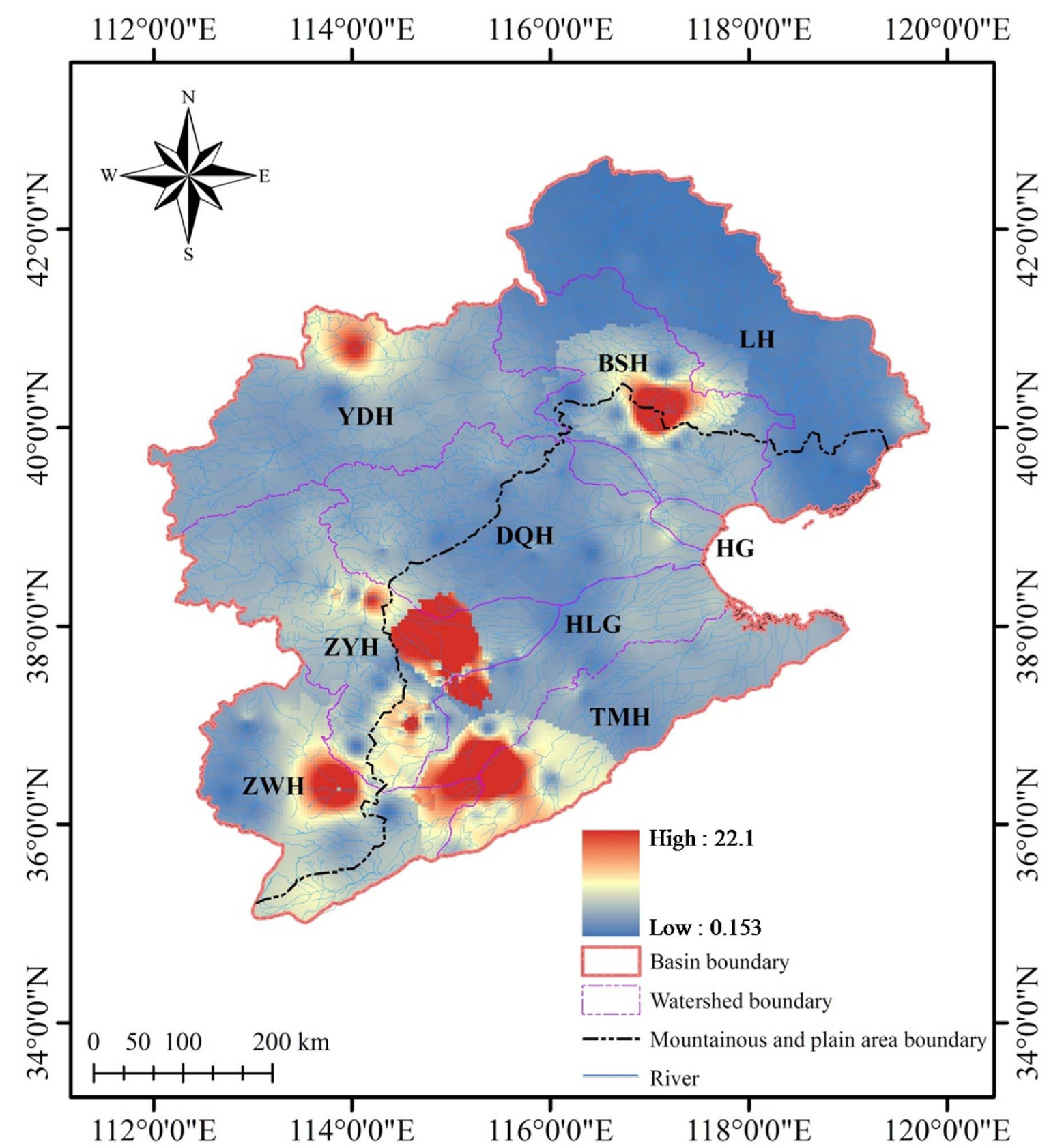

Fig. 2. Total cadmium (Cd) concentrations $(\mathrm{mg} / \mathrm{kg}$ ) in the surface riverine sediments of the Haihe Basin, north China.

study area was assessed using $E_{r}^{i}$ and the RAC. Potential ecological risk (PER) represents the sensitivity of the biological community to a given substance and indicates the risk posed by heavy metals (Fu et al., 2014; Ma et al., 2013). Calculated PER indices of Cd $\left(E_{r}^{i}\right)$ for this study are presented in Fig. 5. In the Haihe Basin, the $E_{r}^{i}$ values of Cd in the sediments ranged from 47.3 to 6869 , with an average of 334 , indicating very high PER related to $\mathrm{Cd}$ in the riverine sediments. These findings were consistent with the EF and $I_{\text {geo }}$ results. Cd in these sediments was associated with a very high PER in $16.81 \%$ of the sampling sites; while high PER values were recorded for $48.64 \%$, considerable PER for $22.73 \%$, and a moderate PER for $11.82 \%$ of sites.

Heavy metals are bound to/on carriers (e.g., carbonate, organic matter, sulfides, and $\mathrm{Fe} / \mathrm{Mn}$ oxides) in the sediments; these are defined as different fractions, whereby their binding strength determines their bioavailability and the risk associated with their presence in aquatic ecosystems (Nemati et al., 2011). Here, the RAC was determined using the percentage of Cd occurring in the B1 fraction. This is because $\mathrm{Cd}$ weakly bound to the solid phase usually poses a greater risk to the aquatic environment (Jain, 2004). In this study, 18.11\% (mean value) of the total Cd occurred in the B1 fraction (Fig. S2). The high proportion of metals in this fraction is indicative of anthropogenic pollution (Weng et al., 2014; Yang et al., 2009). According to the RAC classification shown in Table S3, Cd in the surface riverine sediments is associated with a very high or high risk in $10.45 \%$ of sampling sites; while a medium risk occurred in $50.91 \%$, low risk in $36.36 \%$; and no risk in only $2.20 \%$ of sampling sites. Therefore, significant Cd remediation measures should be carried out as soon as possible on the riverine sediments of the Haihe Basin, especially in the junction region of HLG, $\mathrm{TMH}$, and ZWH watersheds, according to the results of both $E_{r}^{i}$ and the RAC.

The bioavailability and ecotoxicity of heavy metals are directly dependent on their speciation in sediments (Dong et al., 2013). Thus, the bioavailability and ecotoxicity of heavy metals can be described in terms of various fractions: metals occurring in the B1 and B2 fractions 

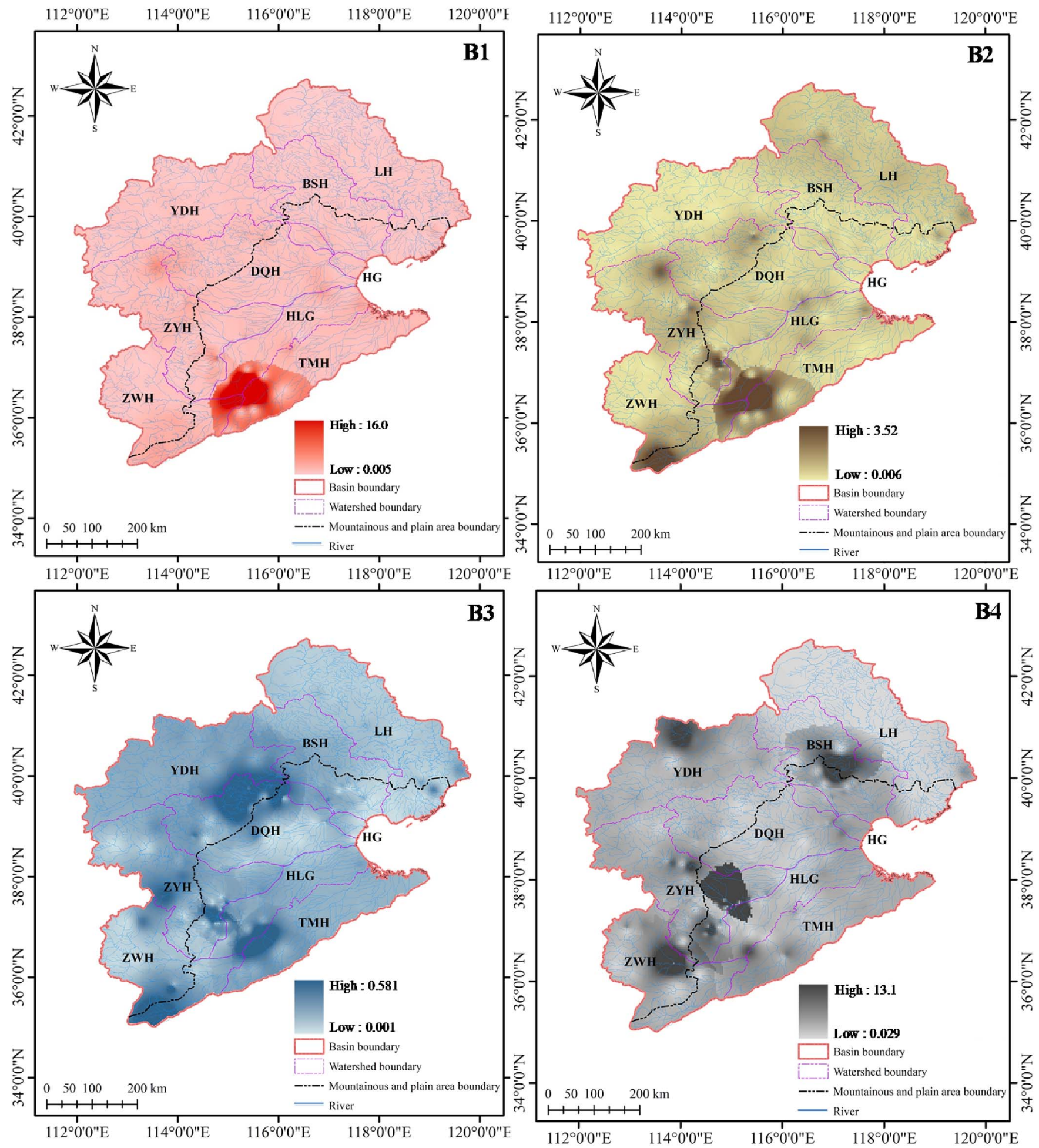

Fig. 3. Cadmium (Cd) concentrations $(\mathrm{mg} / \mathrm{kg}$ ) in different extraction fractions of the surface riverine sediments of the Haihe Basin, north China.

are directly bioavailable and are the most toxic; metals in the B3 fraction are potentially bioavailable and toxic, with the likelihood of their bioavailability increasing over time; while metals in the B4 fraction appear to be nontoxic (Yuan et al., 2011). In this study, the percentage of Cd occurring in the bioavailable fractions (B1 + B2 + B3) was $51.58 \%$ in the surface riverine sediments, with mean concentrations of these fractions reaching $0.557 \mathrm{mg} / \mathrm{kg}$ (Fig. S7). The high $\mathrm{Cd}$ content of these bioavailable fractions demonstrates that $\mathrm{Cd}$ poses an ecological risk to the environment in the study area.
SQGs and $Q_{m-P E C}$ values were used to further examine the ecotoxicity of $\mathrm{Cd}$ in the sediments of the Haihe Basin (Fig. S8 and Fig. 5). Cd concentrations exceeded the background values in $100 \%$ of the sampling sites, indicating that $\mathrm{Cd}$ had varying accumulation degrees in all the riverine sediments of the Haihe Basin. In particular, 33.64\% of sediments had concentrations that exceeded the threshold effect concentration (TEC), while $2.73 \%$ had concentrations exceeding the probable effect concentration (PEC) (Fig. S7). Based on these results, adverse effect of Cd was expected in this environment. The $Q_{m-P E C}$ can 

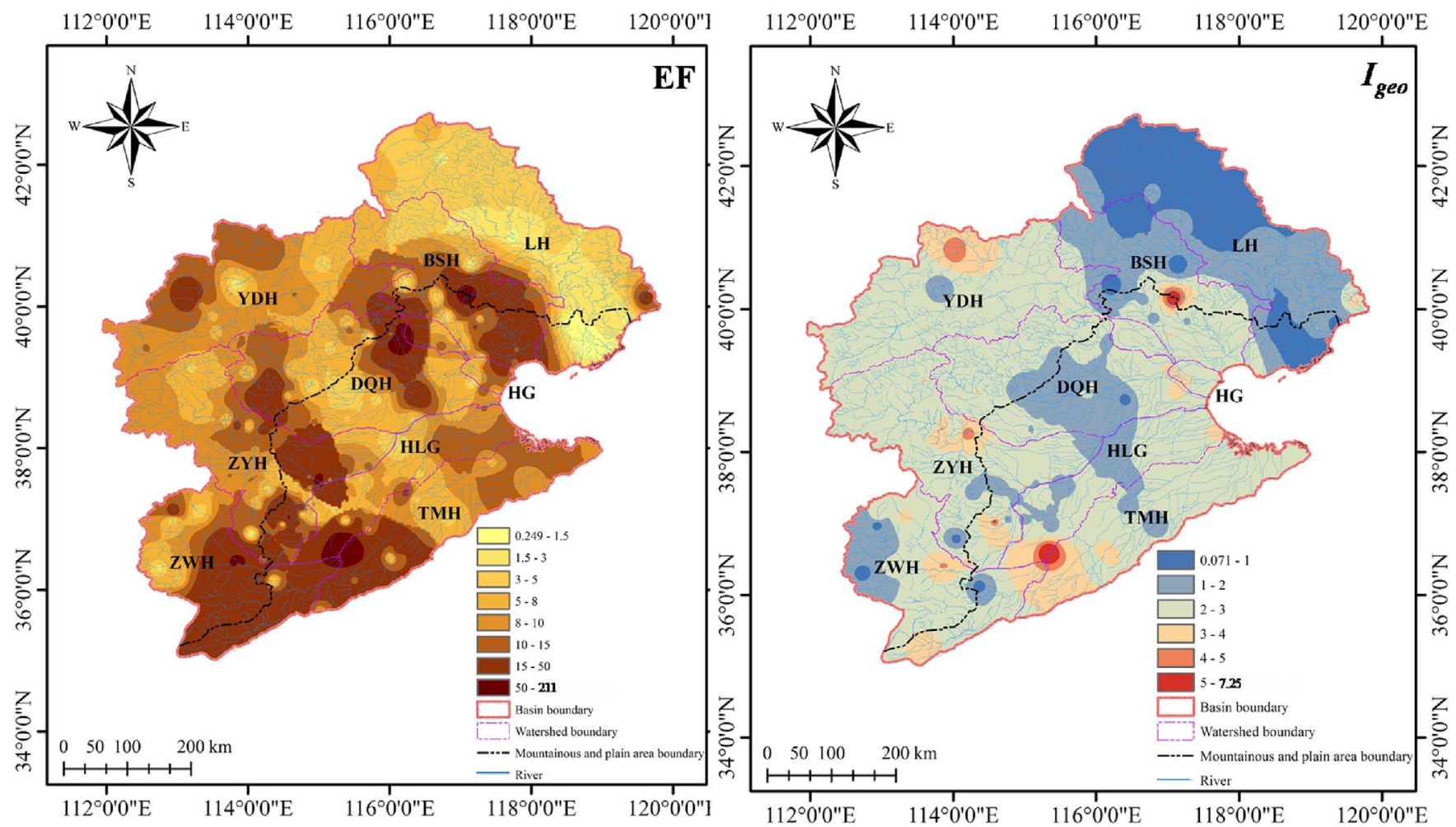

Fig. 4. Cadmium (Cd) enrichment factor (EF) and geo-accumulation index $\left(I_{\text {geo }}\right)$ values of surface riverine sediments in the Haihe Basin, north China.
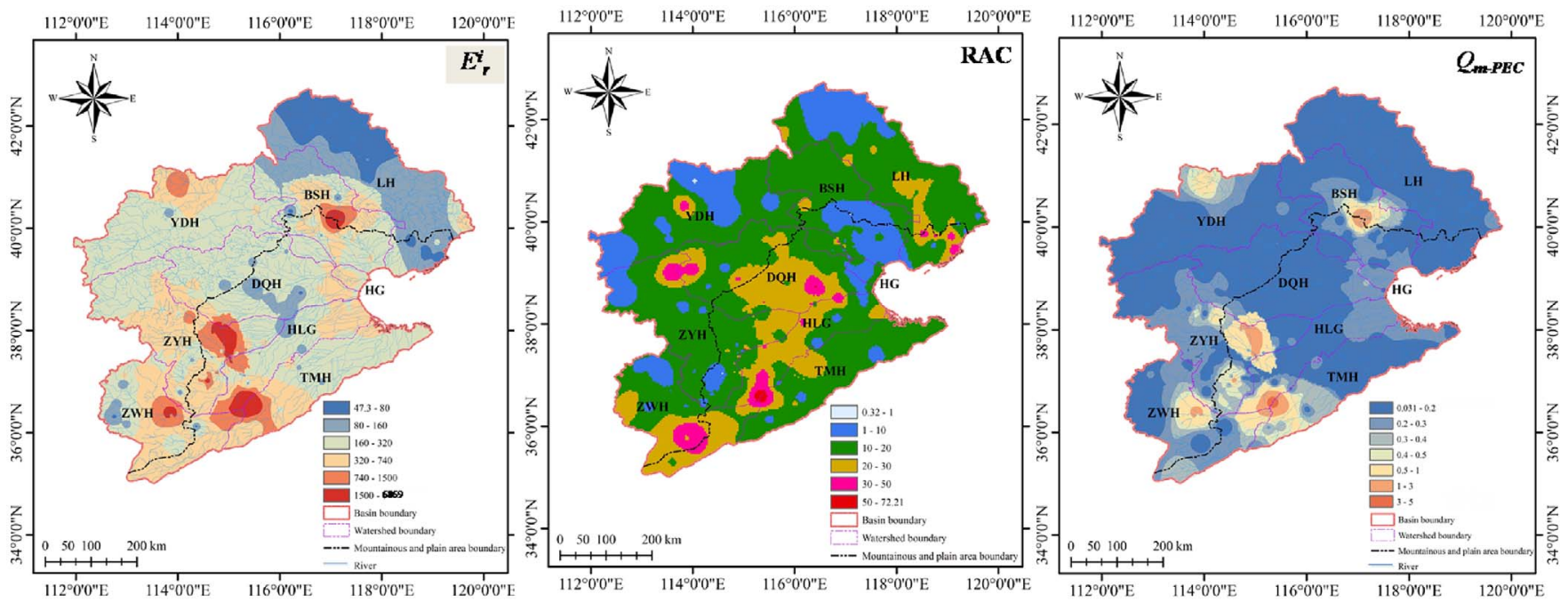

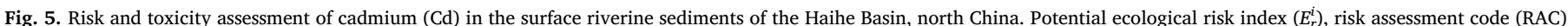
and mean probable effect concentration quotient $\left(Q_{m-P E C}\right)$ values are shown.

be used as an index of sediment toxicity associated with heavy metals. A $Q_{m-P E C}$ value below 0.5 indicates that the surface sediment is not toxic to benthic organisms, while a $Q_{m-P E C}>1.5$ indicates that adverse effects on benthic organisms are likely to occur. In this study, $Q_{m-P E C}$ values ranged from 0.031 to 4.46 , with an average value of 0.217 (Fig. 5). Specifically, there were five regions with high $Q_{m-P E C}$ values, yielding a similar spatial distribution to total $\mathrm{Cd}$ concentrations in the Haihe Basin.

In the riverine sediments of the Haihe Basin, Cd has reached very high levels (maximum value $=22.1 \mathrm{mg} / \mathrm{kg}$ ), indicating a high degree of anthropogenically-derived $\mathrm{Cd}$ accumulation (maximum EF value $=211$ ), especially in the plain and coastal regions (Fig. 3). These sources may include mining and industrial activities, as well as agricultural ones. Especially in the plain and coastal regions of the Haihe
Basin, Cd pollution, risk, and toxicity of surface riverine sediments are all high, as indicated by the high percentage of Cd occurring in the bioavailable fraction (average value $=51.58 \%$ ). Such high bioavailability may lead to adverse impacts on human and ecosystem health (Lambert et al., 2007; Zhao et al., 2007).

\section{Conclusions}

Cd concentrations, speciation, sources, pollution, risk, and toxicity were assessed in surface riverine sediments of the Haihe Basin of north China. Total Cd concentrations (from 0.153 to $22.1 \mathrm{mg} / \mathrm{kg}$ ) in the sediments all exceeded the soil background value. The five regions with the highest $\mathrm{Cd}$ concentrations were the northern region of the YDH watershed, the central region of the BSH watershed, the eastern region 
of the ZYH watershed, the eastern region of the ZWH watershed, and the junction region of the HLG, TMH, and ZWH watersheds. According to $\mathrm{EF}$ and $I_{g e o}$ values, Cd appeared to have been derived from anthropogenic sources in most of the riverine sediments of the Haihe Basin, especially in the plain and coastal regions, where sediments were polluted with Cd to a high degree. Additionally, based on both total concentrations and speciation, Cd posed a risk in all sediments sampled in this study, and was highly bioavailable, which may result in adverse effects on the benthic organisms in the rivers. The results of this study will be useful in the development of effective control strategies for Cd pollution in riverine sediments of the Haihe Basin.

\section{Acknowledgements}

This research was supported by the Youth Innovation Promotion Association CAS (Wenzhong Tang, 2017059), the Major Science and Technology Program for Water Pollution Control and Treatment (No. 2012ZX07203-006), and the special fund from the State Key Joint Laboratory of Environment Simulation and Pollution Control (Project No. 17L02ESPC). We also acknowledge the support received by Wenzhong Tang from the Chinese Scholarship Council (CSC Grant 201604910224).

\section{Appendix A. Supplementary data}

Supplementary data associated with this article can be found, in the online version, at http://dx.doi.org/10.1016/j.ecolind.2017.06.011.

\section{References}

Arain, M.B., Kazi, T.G., Jamali, M.K., Afridi, H.I., Jalbani, N., Sarfraz, R.A., Baig, J.A., Kandhro, G.A., Memon, M.A., 2008. Time saving modified BCR sequential extraction procedure for the fraction of $\mathrm{Cd}, \mathrm{Cr}, \mathrm{Cu}, \mathrm{Ni}, \mathrm{Pb}$ and $\mathrm{Zn}$ in sediment samples of polluted lake. J. Hazard. Mater. 160, 235-239.

Bao, S.D., 2000. Soil and Agricultural Chemical Analysis. Chinese Agricultural Publisher, Beijing, China.

Bhuiyan, M.A.H., Parvez, L., Islam, M.A., Dampare, S.B., Suzuki, S., 2010. Heavy metal pollution of coal mine-affected agricultural soils in the northern part of Bangladesh. J. Hazard. Mater. 173, 384-392.

Chai, Y., Guo, J., Chai, S.L., Cai, J., Xue, L.F., Zhang, Q.W., 2015. Source identification of eight heavy metals in grassland soils by multivariate analysis from the Baicheng. Songyuan area, Jilin Province, Northeast China. Chemosphere 134, 67-75.

Cheng, W.H., Yap, C.K., 2015. Potential human health risks from toxic metals via mangrove snail consumption and their ecological risk assessments in the habitat sediment from Peninsular Malaysia. Chemosphere 135, 156-165.

Christophoridis, C., Dedepsidis, D., Fytianos, K., 2009. Occurrence and distribution of selected heavy metals in the surface sediments of Thermaikos Gulf, N. Greece. Assessment using pollution indicators. J. Hazard. Mater. 168, 1082-1091.

Ding, Y.K., Shan, B.Q., Zhao, Y., 2015. Assessment of river habitat quality in the Hai River Basin, Northern China. Int. J. Environ. Res. Public Health 12, 11699-11717.

Dong, B., Liu, X.G., Dai, L.L., Dai, X.H., 2013. Changes of heavy metal speciation during high-solid anaerobic digestion of sewage sludge. Bioresour. Technol. 131, 152-158.

Dragovic, S., Mihailovic, N., Gajic, B., 2008. Heavy metals in soils: distribution, relationship with soil characteristics and radionuclides and multivariate assessment of contamination sources. Chemosphere 72, 491-495.

Fu, J., Zhao, C.P., Luo, Y.P., Liu, C.S., Kyzas, G.Z., Luo, Y., Zhao, D.Y., An, S.Q., Zhu, H.L., 2014. Heavy metals in surface sediments of the Jialu River, China: their relations to environmental factors. J. Hazard. Mater. 270, 102-109.

Galunin, E., Ferreti, J., Zapelini, I., Vieira, I., Tarley, C.R.T., Abrao, T., Santos, M.J., 2014. Cadmium mobility in sediments and soils from a coal mining area on Tibagi River watershed: environmental risk assessment. J. Hazard. Mater. 265, 280-287.

Gao, X.L., Chen, C.T.A., 2012. Heavy metal pollution status in surface sediments of the coastal Bohai Bay. Water Res. 46, 1901-1911.

Gao, B., Zhou, H.D., Liang, X.R., Tu, X.L., 2013. Cd isotopes as a potential source tracer of metal pollution in river sediments. Environ. Pollut. 181, 340-343.

Guo, W.H., Liu, X.B., Liu, Z.G., Li, G.F., 2010. Pollution and potential ecological risk evaluation of heavy metals in the sediments around Dongjiang Harbor, Tianjin. Procedia Environ. Sci. 2, 729-736.

Hakanson, L., 1980. An ecological risk index for aquatic pollution control. A sedimentological approach. Water Res. 14, 975-1001.
He, M.C., Wang, Z.J., Tang, H.X., 1998. The chemical, toxicological and ecological studies in assessing the heavy metal pollution in Le An River, China. Water Res. 32, 510-518.

Jain, C.K., 2004. Metal fractionation study on bed sediments of River Yamuna, India. Water Res. 38, 569-578.

Kucuksezgin, F., Uluturhan, E., Batki, H., 2008. Distribution of heavy metals in water, particulate matter and sediments of Gediz River (Eastern Aegean). Environ. Monit. Assess. 141, 213-225.

Lambert, R., Grant, C., Sauve, S., 2007. Cadmium and zinc in soil solution extracts following the application of phosphate fertilizers. Sci. Total Environ. 378, 293-305.

Li, R.Z., Shu, K., Luo, Y.Y., Shi, Y., 2010. Assessment of heavy metal pollution in estuarine surface sediments of Tangxi River in Chaohu Lake Basin. Chin. Geogr. Sci. 20, 9-17.

Liu, J.L., Li, Y.L., Zhang, B., Cao, J.L., Cao, Z., Domagalski, J., 2009. Ecological risk of heavy metals in sediments of the Luan River source water. Ecotoxicology 18, 748-758.

Ma, Z., Chen, K., Yuan, Z., Bi, J., Huang, L., 2013. Ecological risk assessment of heavy metals in surface sediments of six major Chinese freshwater lakes. J. Environ. Qual. 42, 341-350.

MacDonald, D.D., Ingersoll, C.G., Berger, T.A., 2000. Development and evaluation of consensus-based sediment quality guidelines for freshwater ecosystems. Arch. Environ. Contam. Toxicol. 39, 20-31.

Nemati, K., Abu Bakar, N.K., Abas, M.R., Sobhanzadeh, E., 2011. Speciation of heavy metals by modified BCR sequential extraction procedure in different depths of sediments from Sungai Buloh Selangor, Malaysia. J. Hazard. Mater. 192, 402-410.

Nobi, E.P., Dilipan, E., Thangaradjou, T., Sivakumar, K., Kannan, L., 2010. Geochemical and geo-statistical assessment of heavy metal concentration in the sediments of different coastal ecosystems of Andaman Islands, India. Estuarine Coastal Shelf Sci. 87, 253-264.

Perin, G., Craboledda, L., Lucchese, M., Cirillo, R., Dotta, L., Zanetta, M.L., Oro, A.A. 1985. Heavy metal speciation in the sediments of Northern Adriatic Sea: a new approach for environmental toxicity determination. In: Lakkas, T.D. (Ed.), Heavy Metals in the Environment. Edinburg, pp. 454-456.

Quenea, K., Lamy, I., Winterton, P., Bermond, A., Dumat, C., 2009. Interactions between metals and soil organic matter in various particle size fractions of soil contaminated with waste water. Geoderma 149, 217-223.

Shang, L.Y., Sun, R.H., Wang, Z.M., Ji, Y.H., Chen, L.D., 2012. Assessment of heavy metal pollution in surface sediments of rivers in northern area of Haihe River Basin, China. Environ. Sci. 33, 606-611 (in chinese).

Su, H.C., Q, S.B., Tang, W.Z., Wang, L.S., Wang, W.M., 2015. Heavy metal pollution of the surface sediments in a typical clean river system of Haihe Basin. Acta Sci. Circumst. 35, 2860-2866 (in chinese).

Tang, W.Z., Zhao, Y., Wang, C., Shan, B.Q., Cui, J.G., 2013. Heavy metal contamination of overlying waters and bed sediments of Haihe Basin in China. Ecotoxicol. Environ. Saf. 98, 317-323.

Tang, W.Z., Shan, B.Q., Zhang, H., Zhang, W.G., Zhao, Y., Ding, Y.K., Rong, N., Zhu, X.L., 2014. Heavy metal contamination in the surface sediments of representative limnetic ecosystems in eastern China. Sci. Rep. 4, 7152.

Tessier, A., Campbell, P.G.C., Bisson, M., 1979. Sequential extraction procedure for the speciation of particulate trace metals. Anal. Chem. 51, 844-851.

Water Resources Protection Bureau of the Hai River Basin (WRPBHRB), 2011. The Water Resources Bulletin of the Hai River Basin. China Water Resources \& Hydropower Press, Beijing.

Weng, H., Ma, X., Fu, F., Zhang, J., Liu, Z., Tian, L., Liu, C., 2014. Transformation of heavy metal speciation during sludge drying: mechanistic insights. J. Hazard. Mater. 265, 96-103.

Yang, Z., Wang, Y., Shen, Z., Niu, J., Tang, Z., 2009. Distribution and speciation of heavy metals in sediments from the mainstream, tributaries, and lakes of the Yangtze River catchment of Wuhan, China. J. Hazard. Mater. 166, 1186-1194.

Yi, Y.J., Yang, Z.F., Zhang, S.H., 2011. Ecological risk assessment of heavy metals in sediment and human health risk assessment of heavy metals in fishes in the middle and lower reaches of the Yangtze River basin. Environ. Pollut. 159, 2575-2585.

Yuan, X.Z., Huang, H.J., Zeng, G.M., Li, H., Wang, J.Y., Zhou, C.F., Zhu, H.N., Pei, X.K., Liu, Z.F., Liu, Z.T., 2011. Total concentrations and chemical speciation of heavy metals in liquefaction residues of sewage sludge. Bioresour. Technol. 102, 4104-4110.

Zhang, H., Shan, B.Q., 2008. Historical records of heavy metal accumulation in sediments and the relationship with agricultural intensification in the Yangtze-Huaihe region, China. Sci. Total Environ. 399, 113-120.

Zhang, W.G., Feng, H., Chang, J.N., Qu, J.G., Xie, H.X., Yu, L.Z., 2009. Heavy metal contamination in surface sediments of Yangtze River intertidal zone: an assessment from different indexes. Environ. Pollut. 157, 1533-1543.

Zhang, C., Yu, Z.G., Zeng, G.M., Jiang, M., Yang, Z.Z., Cui, F., Zhu, M.Y., Shen, L.Q., Hu, L., 2014. Effects of sediment geochemical properties on heavy metal bioavailability. Environ. Int. 73, 270-281.

Zhao, Y., Marriott, S., Rogers, J., Iwugo, K., 1999. A preliminary study of heavy metal distribution on the floodplain of the River Severn, UK by a single flood event. Sci. Total Environ. 244, 219-231.

Zhao, L.Y.L., Schulin, R., Nowack, B., 2007. The effects of plants on the mobilization of Cu and Zn in soil columns. Environ. Sci. Technol. 41, 2770-2775. 